\title{
Visual outcome of cataract surgery at Gondar University Hospital Tertiary Eye Care and Training Center, North West Ethiopia
}

This article was published in the following Dove Press journal:

Clinical Optometry

10 January 2017

Number of times this article has been viewed

\author{
Mohammed Seid Hussen' \\ Kbrom Legesse \\ Gebreselassie' \\ Mohammed Assen Seid ${ }^{2}$ \\ Gizachew Tilahun Belete' \\ 'Department of Optometry, \\ 2Department of Clinical Pharmacy, \\ College of Medicine and Health \\ Sciences, University of Gondar, \\ Gondar, Ethiopia
}

Background: Globally, cataract is the leading cause of blindness which accounts for $51 \%$ of 39 million blind people. The visual rehabilitation is made through sight-restoring surgery. The patients' postoperative visual satisfaction, vision related quality of life, ability to function in daily activities and their overall productivity mainly depend on the visual outcome. However, there are limited data on the visual outcome and its associated factors in the study area. Therefore, this study intended to evaluate the postoperative level of visual acuity to provide a baseline information regarding visual outcome and design a standardized protocol to maximize it.

Methods and materials: A hospital-based cross-sectional study was conducted at the Gondar University Hospital Tertiary Eye Care and Training Center on 223 patients who underwent cataract surgery, selected using simple random technique from April to June 2015.

Results: This study consisted of 218 patients or eyes that underwent cataract surgery. The median age of the participants was 65 years with an interquartile range of 20 years. Of 218 cataract-operated visually impaired eyes $(<6 / 60), 26.6 \%$ of them achieved good visual acuity ( $\geq 6 / 18), 28.9 \%$ of them had borderline acuity $(<6 / 18-6 / 60)$, and the remaining of $44.5 \%$ were remained as poor visual acuity $(<6 / 60)$. It has been observed that the postoperative visual acuity had an association with postoperative follow up time duration $(P=0.035)$.

Conclusion: In this study, the visual outcome of cataract surgery was significantly low as compared to World Health Organization's recommendations, and it has been recognized that there is significant progression of visual acuity in different consecutive weeks.

Keywords: cataract surgery, visual outcome, Gondar, Ethiopia

\section{Introduction}

Cataract is the leading cause of blindness globally, particularly in developing countries. Currently, it accounts for $51 \%$ of 39 million blind people worldwide, $90 \%$ of them living in low- and middle-income countries. ${ }^{1-3}$ The visual rehabilitation is made through sight-restoring surgery. In recent years, the number of people who undergo cataract surgery has increased rapidly and it becomes the most frequently performed cost-effective surgical procedure throughout the world. ${ }^{4-6}$

The outcome of cataract surgery for an individual or for a defined population is therefore as important as measuring the quantity of surgical operations performed. The outcome of cataract surgery can be measured through postoperative level of visual acuity, ability to function, quality of life, and economic rehabilitation. ${ }^{7}$ Since the patients' visual satisfaction, vision related quality of life, ability to function in daily activities and their overall productivity mainly depend on the visual outcome, the World Health Organization (WHO) recommends that poor (best corrected visual
Correspondence: Mohammed Seid Hussen

Department of Optometry, College of Medicine and Health Sciences, University of Gondar, P.O. Box 196, Gondar, Ethiopia

Tel +25I 92 I27 5287

Email mohamiaseid@gmail.com
Clinical Optometry 2017:9 19-23 
acuity [BCVA] $<6 / 60$ ) or borderline (BCVA $<6 / 18$ ) visual outcomes after cataract surgery should not be $>10 \%$ to $20 \%{ }^{8}$ Furthermore, several studies revealed that about $30 \%-50 \%$ of cataract-operated eyes cannot see $6 / 60(=20 / 200 ; 0.1)$ with the correction available to them, and the visual outcome of cataract surgery does not meet the individual's daily visual demand. ${ }^{79}$ This can be due to concurrent sight impairing eye diseases, early surgical complications, inadequate optical correction, or long-term complications..$^{10}$ This is the main reason why cataract patients do not come forward for cataract surgery due to "fear of losing sight".

However, this study aimed to evaluate the visual outcome of cataract surgery by controlling such presumed factors except surgically induced change in corneal curvatures, pupil size, pupil regularity, anterior chamber depth, and other ocular parameters. It is also assumed that change in ocular parameters affect the optical properties of the eye.

Overall, the outcome of this study provides a baseline information for the clinicians and researchers to design a standardized protocol to maximize the surgical visual outcome.

\section{Methods and materials Study design}

A hospital-based cross-sectional study was conducted on 223 patients from April 20, 2015 to June 20, 2015, at the Gondar University Hospital Tertiary Eye Care and Training Center, North West Ethiopia. This eye care center provides a comprehensive clinical and community eye health services for eight zones and serve as a major referral center for 14 million people living in North West Ethiopia. ${ }^{11}$ It is estimated that a minimum of 720 patients utilize cataract surgery service per year. This study included all patients who underwent cataract surgery from September 2014 to March 2015 at the Gondar University Hospital Tertiary Eye Care and Training Center. However, those patients who had ocular comorbidity such as glaucoma, age-related macular degeneration, corneal opacity, intra- or postoperative complications, previous history of ocular trauma, and systemic health problems as in diabetes mellitus and hypertension were excluded from the study.

\section{Sample size determination}

The study participants were selected by using simple random technique. The sample size was determined using single population proportion formula with an assumption of $95 \%$ confidence level, 5\% margin of error, and proportion of poor visual acuity among cataract-operated eyes (30\%) from a similar study done in Goro District Hospital, Central Ethiopia. ${ }^{12}$ This calculation indicated that 323 participants were needed to determine the level of postoperative visual acuity. However, the source population during this study period was $<10,000$ so that the reduction formula was applied to obtain the adequate minimum sample size. Thus, the final planned sample size was 223 .

\section{Data collection procedures}

Data were collected by trained graduate class optometry students using a well-organized data extraction format that consisted of sociodemographic data, clinical characteristics of the study subjects, pre- and postoperative visual acuity through document review. The preoperative evaluations including anterior segment slit lamp examination, dilated fundus examination, and biometry (keratometry and A-scan) were conducted by ophthalmology residents. The surgical procedure for all eligible study participants was done by senior ophthalmologists. The level of both pre- and postoperative visual acuity was categorized using WHO classification as good visual acuity $(6 / 6-6 / 18)$, borderline visual acuity $(<6 / 18-6 / 60)$, and poor visual acuity $(<6 / 60)$. It was measured using 6 meter Snellen's vision chart. For those who could not read letters at 6 meter, their vision was measured by moving the chart as close as possible. Finally, for those who could not see any letter, counting finger and hand motion were used to measure their vision. The postoperative evaluations were performed by the surgeon who operated the case.

\section{Data processing and analysis}

After the collected data was checked for completeness and consistency, it was coded and entered into Epidata version 3.1 and analyzed by SPSS version 16. Both descriptive and analytical tests were performed. Proportions and summary statistics such as median and interquartile range were computed for some variables of the study. Chi-square test was applied to test any association between independent and dependent variables. Finally, the analyzed data was organized and presented with tabular, graphical, and narrative form as necessary.

\section{Ethical consideration}

Ethical approval was obtained from the College of Medicine and Health Sciences ethical review committee, University of Gondar for this study. The study also followed the principles outlined in the Declaration of Helsinki. After the purpose of the study was described, written informed consent from each of the participant was deemed not required by the ethical review committee of the University of Gondar. The participant's consent was waived because this was a retrospective study through document review. Confidentiality of the 
information was assured by storing the file, through assigning a code number and omitting the patients' name.

\section{Results}

\section{Sociodemographic characteristics of study subjects}

A total of 223 cases that underwent cataract surgery at the Gondar University Hospital Tertiary Eye Care and Training Center were evaluated for their postoperative visual outcome, and five of them were excluded because of data incompleteness. The median age of the study subjects was 65 years with interquartile range of 20 years. Nearly half of the study subjects were males (56\%). The majority of the study subjects were unable to read and write $(77 \%)$ and living in rural areas $(67.89 \%)$ (Table 1$)$.

\section{Clinical characteristics of the study subjects}

Among the total of 218 cataract-operated eyes, $63.8 \%$ of eyes had lenticular opacity involving all layers followed by cortical cataract and posterior subcapsular cataract (PSC) (23.85\%). Nearly $91.74 \%$ of eyes with cataract received small incision cataract surgery (SICS) with posterior chamber intraocular lens (PCIOL) surgical technique, and the rest of them were operated using extracapsular cataract extraction (ECCE) with PC IOL. Almost two-thirds of the study participants had postoperative follow-up visit of 1 up to 4 weeks (Table 2).

\section{Pre- and postoperative visual acuity of the study subjects}

Nearly, $99 \%$ of cataract-operated eyes had poor vision preoperatively $(<6 / 60)$. After the surgery has been done, $26.6 \%$ of operated eyes had achieved good visual acuity, $28.9 \%$ of eyes

Table I Sociodemographic characteristics of study subjects at the Gondar University Hospital Tertiary Eye Care and Training Center, North West Ethiopia, 2015

\begin{tabular}{ll}
\hline Variables & Frequency (\%) \\
\hline Age (years) & \\
$\leq 55$ & $59(26.87)$ \\
$>55$ & $159(72.94)$ \\
Sex & \\
$\quad$ Male & $122(55.96)$ \\
$\quad$ Female & $96(44.04)$ \\
Educational status & \\
Cannot read and write & $168(77.06)$ \\
Can read and write & $50(22.94)$ \\
Residence & \\
$\quad$ Urban & $70(32.11)$ \\
Rural & $148(67.89)$ \\
\hline
\end{tabular}

Table 2 Clinical characteristics of the study subject at the Gondar University Hospital Tertiary Eye Care and Training Center, North West Ethiopia, 2015

\begin{tabular}{ll}
\hline Variables & Frequency (\%) \\
\hline Type of cataract & \\
Cortical+PSC & $52(23.85)$ \\
Nuclear+PSC & $28(12.84)$ \\
Mixed & $138(63.8)$ \\
Type of surgery & \\
SICS+PC IOL & $200(91.74)$ \\
ECCE+PC IOL & $18(8.26)$ \\
Follow-up visit (weeks) & \\
I-4 & $140(64.22)$ \\
$5-8$ & $56(25.6)$ \\
$>8$ & $22(10.1)$ \\
\hline
\end{tabular}

Abbreviations: ECCE, extracapsular cataract extraction; PC IOL, posterior chamber intraocular lens; PSC, posterior subcapsular cataract; SICS, small incision cataract surgery.

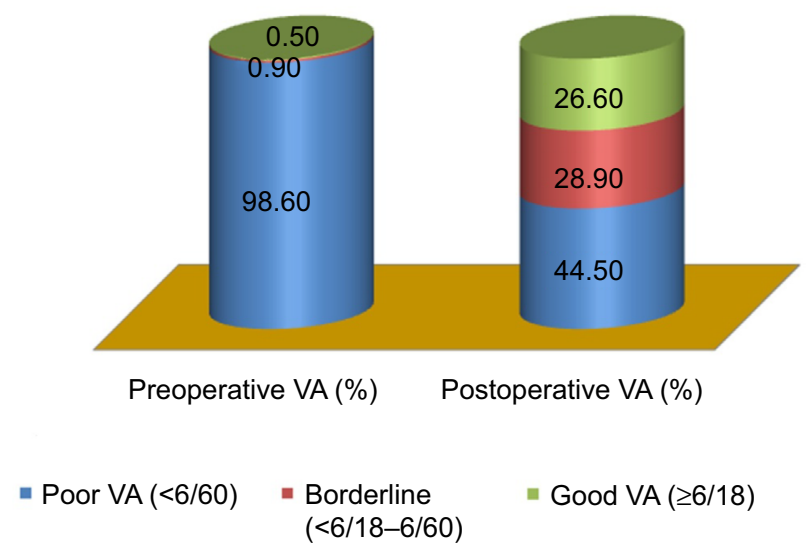

Figure I Level of pre- and postoperative visual acuity at the Gondar University Hospital Tertiary Eye Care and Training Center, North West Ethiopia, 2015. Abbreviation: VA, visual acuity.

had borderline visual acuity, and the remaining of $44.5 \%$ of cataract-operated eyes were remained as poor visual acuity (Figure 1).

By applying chi-square test, significant association has been found only between postoperative follow up time duration and the postoperative visual acuity $(P=0.035)$. However, significant association has not been observed between the postoperative visual acuity and sociodemographic and other clinical variables of the study $(P>0.05)$ (Table 3$)$.

\section{Discussion}

It is frequently reported that cataract surgery is a high-volume operation because of high prevalence of cataract and limited alternatives for interventions. Cataract surgery is the only option to restore and rehabilitate visual acuity. However, several studies reported that there are multiple factors that affect the desired surgical outcome. This is another clinical challenge besides the psycho-socioeconomic burden of the 
Table 3 Statistical tests (chi-square) in sociodemographic and clinical characteristics of study patients for postoperative visual acuity at the Gondar University Hospital Tertiary Eye Care and Training Center, North West Ethiopia, 2015

\begin{tabular}{|c|c|c|c|c|c|}
\hline \multirow[t]{2}{*}{ Variables } & \multicolumn{3}{|c|}{ Postoperative visual acuity } & \multirow[t]{2}{*}{ Total } & \multirow[t]{2}{*}{$P$-value } \\
\hline & Good & Borderline & Poor & & \\
\hline \multicolumn{6}{|l|}{ Age (years) } \\
\hline$\leq 55$ & 17 & 16 & 26 & 59 & 0.86 \\
\hline$>55$ & 41 & 47 & 71 & 159 & \\
\hline \multicolumn{6}{|l|}{ Residence } \\
\hline Urban & 17 & 20 & 33 & 70 & 0.83 \\
\hline Rural & 41 & 43 & 64 & 148 & \\
\hline \multicolumn{6}{|l|}{ Educational status } \\
\hline $\begin{array}{l}\text { Cannot read and } \\
\text { write }\end{array}$ & 14 & 16 & 20 & 50 & 0.76 \\
\hline Can read and write & 44 & 47 & 77 & 168 & \\
\hline \multicolumn{6}{|c|}{ Follow-up time duration (weeks) } \\
\hline $1-4$ & 29 & 38 & 73 & 140 & 0.035 \\
\hline $5-8$ & 23 & 19 & 14 & 56 & \\
\hline$>8$ & 6 & 6 & 10 & 22 & \\
\hline \multicolumn{6}{|l|}{ Type of surgery } \\
\hline SICS+PC IOL & 50 & 57 & 93 & 200 & 0.09 \\
\hline $\mathrm{ECCE}+\mathrm{PC} \mathrm{IOL}$ & 7 & 6 & 5 & 18 & \\
\hline \multicolumn{6}{|l|}{ Type of cataract } \\
\hline Cortical+PSC & 13 & 21 & 18 & 52 & 0.15 \\
\hline Nuclear+PSC & 7 & 10 & 11 & 28 & \\
\hline All layers involved & 38 & 32 & 68 & 138 & \\
\hline
\end{tabular}

Abbreviations: ECCE, extracapsular cataract extraction; PC IOL, posterior chamber intraocular lens; PSC, posterior subcapsular cataract; SICS, small incision cataract surgery.

disease. Hence, this study aimed to evaluate the visual outcome of cataract surgery by controlling the presumed factors affecting the outcome as in ocular comorbidity, systemic health problems, and postoperative complications stated by other studies.

In the present study, around $73.4 \%$ of the cataract-operated eyes were remained as visually impaired postoperatively $(<6 / 18)$. Only $26.6 \%$ of cataract-operated eyes have achieved good visual acuity, which is higher than the study done in Goro District, Central Ethiopia, in which visual acuity of $6 / 18$ or better were obtained in $23.7 \%$ of cataract-operated eyes. ${ }^{12}$ However, this result is lower than the study conducted in Gujarat, India (71.4\%), Adelaide, South Australia (41.2\%), Southern China (62.2\%), Kuwait (54\%), Ibadan, Nigeria (78.8\%), Jimma University, Ethiopia (63.4\%), and Menelike II Hospital at Addis Ababa, Ethiopia (70.4\%)..$^{5,13-17}$ These studies were prospective follow-up studies, in which the progression of the surgical outcome was evaluated prospectively till the surgical wound was resolved and attained some level of visual acuity. However, in this study, the postoperative visual acuity was taken from the patients' last follow up visit which was ranged from 1 week to 12 weeks despite two-thirds of the study participants had follow-up visit of 1-4 weeks. This might be the possible reason for the observed difference.

Overall, the level of postoperative visual acuity in this study is significantly lower than the WHO recommendation, which states that at least $90 \%$ of cataract-operated eyes should have a visual acuity of $\geq 6 / 18{ }^{8}$ This indicates that a large number of individuals had highly compromised vision-related quality of life and loss of productivity postoperatively.

Furthermore, it was also attempted to test the association between the level of postoperative visual acuity and some sociodemographic variables and clinical characteristics of study participants. Only postoperative follow-up time duration has shown an association with the level of postoperative visual acuity. A similar result was reported from the studies conducted in Jos, Nigeria, South Ghana, and Adelaide, Australia, in which greater amount of visual acuity change has been recognized in different consecutive weeks. ${ }^{13,18,19}$ This indicates that as the time increase after operation, all acute postoperative complications as in disturbances of aqueous humor, change in pupillary size, regularity, and other ocular parameter changes will be stabilized. This results in stabilization of the visual acuity.

On the other hand, the major factors like ocular comorbidity (glaucoma, corneal opacity), systemic health problems (diabetes mellitus, hypertension), and postoperative complications stated by other studies have been fixed for all cases so that the possible reason for this poor visual outcome might be related to surgically induced corneal astigmatism and other ocular parameter changes as in pupil size, pupil regularity, anterior chamber depth, and intraocular lens position..$^{20,21}$ Previous studies have shown that surgically induced uncorrected refractive error was the most common cause of poor visual outcome after operation. ${ }^{20}$

Overall, this study implicates that greater effort should be exerted to identify the main cause of visual impairment after operation and to devise strategies so as to maximize the level of visual outcome. Even if this study was the first in kind for the area and conducted with large sample size, it was a retrospective study. And it was difficult to observe every postoperative visual progression. Thus, it would be plausible to conduct prospective follow-up study that incorporated associated factors to make it more informative and suitable for interventions.

\section{Conclusion}

In this study, the visual outcome of cataract surgery was significantly low as compared with WHO recommendations, 
and it has been recognized that there is significant progression in visual acuity in different consecutive weeks.

\section{Acknowledgment}

The authors would like to acknowledge University of Gondar for the financial support to conduct this study.

\section{Disclosure}

The authors report no conflicts of interest in this work.

\section{References}

1. World Health Organization. Global data on visual impairments; 2010. Available from: http://www.who.int/blindness/publications/globaldata/ en/. Accessed April 23, 2015.

2. Berhane Y, Worku A, Bejiga A, et al. Prevalence and causes of blindness and low vision in Ethiopia. Ethiopian J Health Dev. 2008;21(3):204-210.

3. Foster A, Gilbert C, Johnson G. Changing patterns in global blindness: 1988-2008. Community Eye Health. 2008;21(67):37-39.

4. Lumme P, Laatikainen LT. Factors affecting the visual outcome after cataract surgery. Int Ophthalmol. 1993;17(6):313-319.

5. Huang W, Huang G, Wang D, Yin Q, Foster PJ, He M. Outcomes of cataract surgery in urban southern China: the Liwan Eye Study. Invest Ophthalmol Vis Sci. 2011;52(1):16-20.

6. Limburg H, Foster A, Gilbert C, Johnson GJ, Kyndt M. Routine monitoring of visual outcome of cataract surgery. Part 1: development of an instrument. Br J Ophthalmol. 2005;89(1):45-49.

7. Bachani D, Gupta SK, Murthy GV, Jose R. Visual outcomes after cataract surgery and cataract surgical coverage in India. Int Ophthalmol. 1999;23(1):49-56.

8. World Health Organization. Informal Consultation on Analysis of Blindness Prevention Outcomes. Geneva, Switzerland: WHO; 1988:/ PBL/98.68.
9. Limburg H, Foster A, Vaidyanathan K, Murthy G. Monitoring visual outcome of cataract surgery in India. Bull World Health Organ. 1999; 77(6):455-460.

10. Matta S, Park J, Shantha GPS, Khanna RC, Rao GN. Cataract surgery visual outcomes and associated risk factors in secondary level eye care centers of LV Prasad Eye Institute, India. PLoS One. 2016;11(1):e0144853.

11. Tertiary Eye Care Center. Available from: http://www.uog.edu.et. Accessed October 11, 2015.

12. Bejiga A, Tadesse S. Cataract surgical coverage and outcome in Goro District, Central Ethiopia. Ethiop Med J. 2008;46(3):205-210.

13. Mönestam E, Wachmeister L. Impact of cataract surgery on the visual ability of the very old. Am J Ophthalmol. 2004;137(1):145-155.

14. Al Salem M, Ismail L. Factors influencing visual outcome after cataract extraction among Arabs in Kuwait. $\mathrm{Br} J$ Ophthalmol. 1987;71(6):458-461.

15. Mpyet C, Langnap L, Akpan S. Outcome and benefits of small incision cataract surgery in Jos, Nigeria. Niger J Clin Pract. 2007;10(2):162-165.

16. Addisu Z, Solomon B. Patients' preoperative expectation and outcome of cataract surgery at Jimma University Specialized Hospital Department of Ophthalmology. Ethiopian J Health Sci. 2011;21(1): 47-56.

17. Haileselassie T, Asefa Y, Bayu S, Bejiga A. Outcome of extra-capsular cataract extraction with posterior chamber intraocular lens implantation performed at a cataract surgical campaign. Ethiopian J Health Dev. 2002;16(1):77-83.

18. Bekibele CO, Fasina O. Visual outcome of traumatic cataract surgery in Ibadan, Nigeria. Nigerian J Clin Pract. 2008;11:4.

19. Ilechie AA, Boadi-Kusi B, Ndudiri O, Ofori E. Evaluation of postoperative visual outcomes of cataract surgery in Ghana. Int J Health Res. 2012;5(1):35-42.

20. Olawoye OO, Ashaye AO, Bekibele CO, Ajayi BG. Visual outcome after cataract surgery at the University College Hospital, Ibadan. Ann Ib Postgrad Med. 2011;9(1):8-13.

21. Lumme P, Laatikainen LT. Factors affecting the visual outcome after cataract surgery. Int Ophthalmol. 1993;17(6):313-319.

\section{Clinical Optometry}

\section{Publish your work in this journal}

Clinical Optometry is an international, peer-reviewed, open access journal publishing original research, basic science, clinical and epidemiological studies, reviews and evaluations on clinical optometry. All aspects of patient care are addressed within the journal as well as the practice of optometry including economic and business analyses. Basic and clinical

\section{Dovepress}

research papers are published that cover all aspects of optics, refraction and its application to the theory and practice of optometry. The manuscript management system is completely online and includes a very quick and fair peer-review system, which is all easy to use. Visit http://www.dovepress. com/testimonials.php to read real quotes from published authors. 